\title{
Analyzes of Flyback DC-DC Converter for Submodule Level Maximum Power Point Tracking in Off-grid Photovoltaic Systems
}

\author{
M.E. BAŞOĞLU
}

\begin{abstract}
Submodule level maximum power point tracking (MPPT) systems have become popular due to its outstanding performance in partial shading conditions (PSCs) and basic algorithm requirement. MPPT is realized by DC-DC converters. They are power processing units between photovoltaic (PV) module and resistive load. Among DC-DC converter topologies, the flyback is a proper choice since it can either increase or decrease the voltage. Furthermore, power level is small in submodule level (SML) MPPT applications. In this study, analyzes and power circuit design of a flyback converter for continuous conduction mode (CCM) is carried out firstly. Then, the performance of the flyback converter on the SML MPPT system and its superiority over the module level MPPT is shown by using same converter topology and perturb and observe (P\&O) algorithm. In order to validate the superior performance of SML MPPT, it is compared with module level MPPT in MATLAB/Simulink environment. Results show that SML MPPT guarantees global MPPT in any PSCs with any kind of basic MPPT algorithm. On the other hand, module level MPPT fails in many PSCs with the same algorithm. According to simulation results, SML MPPT generated more power by $61.2 \%$ in average than module level MPPT systems in simulation studies.
\end{abstract}

Index Terms - Distributed MPPT, flyback, maximum power point tracking, photovoltaic, submodule, MPPT.

\section{INTRODUCTION}

$\mathrm{S}_{\mathrm{u}}^{\mathrm{o}} \mathrm{s}$ OLAR energy is an important renewable energy sources used for generation of electrical energy in standalone and utility scale power systems. Photovoltaic (PV) modules are used in electrical energy generation. Due to the p-n junction in structure, PV modules are similar to a basic diode and their current-voltage (I-V) characteristic curve change logarithmic form. Therefore, obtaining maximum power from a PV module requires a special process [1]. Generally, a power converter is connected between the load and the PV source to extract the maximum power from a module and this converter is generally controlled by an MPPT algorithm [2]. While the

MUSTAFA ENGIN BAŞOĞLU, is with Department of Electrical and Electronics Engineering University of Gümüşhane, Gümüşhane, Turkey,(email: menginbasoglu@gumushane.edu.tr).

(iD https://orcid.org/ 0000-0002-6228-4112

Manuscript received March 23, 2019; accepted June 8, 2019. DOI: $10.17694 /$ bajece. 543668 conventional system can perform MPPT if the solar irradiance received by a PV module surface is uniform; if the PV module panel is partially shaded, it is necessary to increase the number of power converter or to improve the algorithm, to perform MPPT efficiently. Because, a typical PV module has a few bypass diodes and the presence of these diodes cause multipeak structure in power-voltage $(\mathrm{P}-\mathrm{V})$ curves. This makes the tracking of maximum power point (MPP) difficult or inefficient [3].

Distributed MPPT approach presents some advantage for the case that the PV system is not uniformly irradiated. In that approach, PV source is divided into some parts and MPPT is performed individually. For example, in a series connected PV string, each PV module performs its own MPPT which can be considered as a module level MPPT. On the other hand, if each submodule in a PV module performs its own MPPT, it is the SML MPPT. In these approaches, micro inverter and power optimizers are used as a power processing converter.

SML MPPT requires a few power converters with low power scale. Therefore, flyback converters are considerable good choices since they consist of a few components and have a big efficiency in small power level. Furthermore, it can be used in DC-AC and DC-DC converters for micro inverters and power optimizers, respectively. Current sensorless flyback inverter is proposed for small scale PV systems [4]. Although it seems as a cost effective solution, it cannot track MPP in PSCs. Smart PV module concepts are the other type of distributed MPPT (DMPPT) approach. In general, DC-AC converter is connected to the PV module in this approach. Feed forward control scheme is applied to flyback converter to obtain high quality output voltage from the inverter side [5]. For the SML MPPT applications, a novel flyback converter is presented to acquire maximum power from a PV module in PSCs [6]. This converter is used for the MPPT stage of microinverter. Since SML MPPT is realized, requirement of bypass diodes is eliminated and MPPT is performed by a basic algorithm. On the other hand, a current sensorless MPPT control scheme is proposed for interleaved flyback inverters [7]. This technique is complicated but offers a cost effective solution for microinverters. Voltage sensorless MPPT can be used in AC module applications [8], it is shown that voltage sensorless method has similar performance with $\mathrm{P} \& \mathrm{O}$. But it needs less sensor and makes the MPPT cheaper than P\&O. A bidirectional discontinuous mode flyback converter is used as 
a voltage equalizer used in global MPPT [9]. In this study, power processing is very small which increases the total efficiency. Results show that extracted power increases compared with the PV structure owning bypass diodes. A hybrid MPPT method containing conventional short circuit current pulse and $\mathrm{P} \& \mathrm{O}$ algorithm is used in a single stage flyback inverter [10]. However, this method is not capable of tracking of MPP in PSCs.

Submodule integrated DMPPT is proposed in [11]. Buck converter is connected to each cell group and output of the buck converters is connected in series. $20 \%$ of the total energy increase is obtained compared with the module level MPPT. Substring level MPPT is applied and it is resulted that remarkable power increase is obtained [12]. Differential power processing (DPP) is the latest approach aiming to decrease power processing to rise efficiency [13]. In that approach, power converters have small power levels compared with full power processing (FPP). Furthermore, rated value is low and cost of the converters is small [14]. A modified interleaved SEPIC converter is proposed aiming to equalize the voltage of the series connected PV module in the PV string [15]. It is presented that energy improvement ranges from $27 \%$ to $34 \%$. A novel DPP approach is used as a module integrated converter in series connected PV systems [16]. Results show that it performs better than classical PV configurations.

It is surely clear that MPPT efficiency increases from string level to submodule level. In this study, advantages of the SML MPPT are presented by comparing module level MPPT concept. As a power processing unit, flyback converter is selected since flyback converters are the proper choice in small power scale. Comprehensive design of flyback converter operating CCM is presented. The remains of the study continue as follows. In Section II, theoretical analyzes and operation principle of a flyback converter is given. Design steps are also presented in this section. In Section III, SML MPPT structure has been compared with module level MPPT by simulations. These simulation studies are performed in MATLAB/Simulink. In Section IV, simulation results are evaluated briefly. Finally, the main outcomes of the study are summarized and some information about future studies is also mentioned.

\section{PRINCIPLE OF FLYBACK CONVERTERS}

Flyback converters are the most preferred switch mode power supply topologies below $100 \mathrm{~W}$ since they have less components than the other topologies and they can have multiple outputs, if desired [17]. A typical flyback converter consists of transformer for energy storage and voltage conversion, a capacitor, a switching device and a diode as presented in Fig. 1. In flyback converters, transformer, which is also called as coupled inductor, provides galvanic isolation between the primary and secondary side of the transformer. However, its operation is quite different from normal transformer. While the primary winding of the transformer carries current, in the secondary side of the transformer, current cannot flow since the polarity of the secondary winding is reversed.

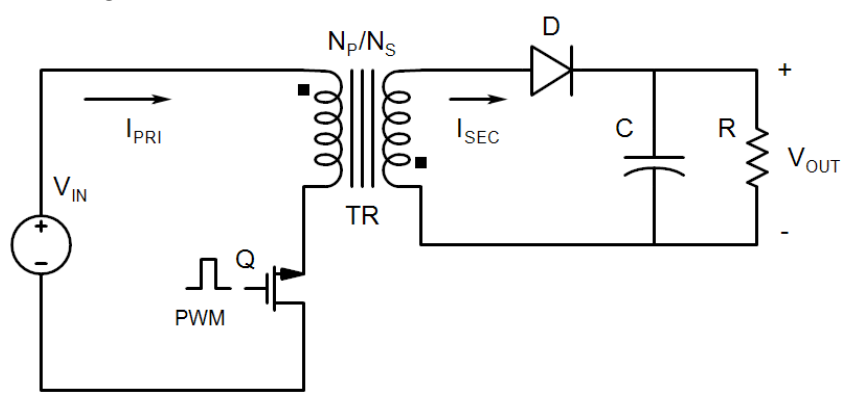

Fig.1. Electrical circuit of flyback converter

\section{A. Operation Modes of Flyback Converters}

There are three types of operation in DC-DC converters. They are CCM, discontinuous conduction mode (DCM) and boundary conduction mode (BCM). Normally, these operations are defined as the value of inductor current in a switching period. In a flyback converter, DC transformer is used as a magnetic energy storage component and there is no additional inductor. Therefore, the operation mode of a flyback is determined by the current continuity of the primary and secondary winding. Operation modes of a flyback converter are presented in Fig. 2.

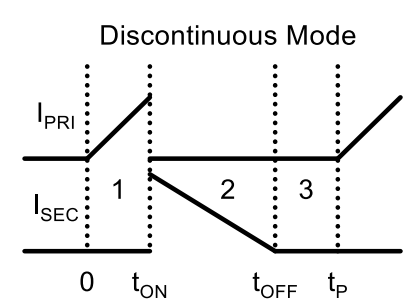

(a)

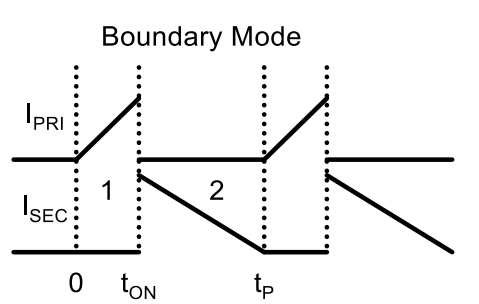

(b)

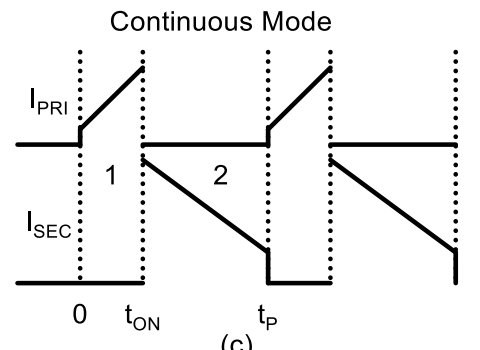

(c)

Fig.2. Operation modes of flyback converters a) Discontinuous b) Boundary c) Continuous

\section{B. Design Steps of Flyback Converter in CCM}

While analyzing the flyback converter, transformer can be modelled by an ideal transformer and magnetizing inductor [18]. This inductor is parallel to the primary winding of the transformer and it is modelled as the energy storage element in the circuit given in Fig. 2. In this circuit, when switch $Q$ is turned on at $\mathrm{t}=0$, magnetizing inductance is stored energy and its current of primary winding increases linearly up to $t=t_{O N}$. The diode is reverse biased due to the polarity of the secondary winding between $\mathrm{t}=0$ and $\mathrm{t}=\mathrm{t}_{\mathrm{ON}}$. So, current of the secondary winding is zero. Output load is supplied by the 
capacitor in this period. The voltage across the magnetizing inductance is formulated as in (1). Primary current is calculated as in [18].

$$
V_{L m}=L_{m} \frac{d i_{L m}}{d t}
$$

In (1), $\mathrm{L}_{\mathrm{M}}$ is the magnetizing inductance. Switch current is equal to a current of magnetizing current when the switch is on. It can be calculated as in (2).

$$
I_{Q}=I_{L m}=I_{p r i}=\frac{V_{I N}+V_{D S(O N)}}{L_{M}} t_{O N}+I_{i n i}
$$

In (2), $I_{Q}$ is the switch current, $I_{L m}$ is the magnetizing current, $\mathrm{I}_{\text {ini }}$ is the initial current of the magnetizing inductor, $\mathrm{V}_{\mathrm{IN}}$ is the input voltage, $\mathrm{V}_{\mathrm{DS}(\mathrm{ON})}$ is the voltage drop on the switch, $t_{O N}$ is the conduction time of the switch. In order to calculate magnetizing inductance, (3) is rearranged as below.

$$
I_{p r i}-I_{i n i}=\Delta I_{L m}=\frac{V_{I N}+V_{D S(O N)}}{L_{M}} t_{O N}
$$

By using (3), magnetizing inductance (inductance of the primary) can be calculated. The reverse voltage of the diode should not be bigger than the maximum reverse voltage between $\mathrm{t}=0$ and $\mathrm{t}=\mathrm{t}_{\mathrm{ON}}$. The maximum reverse voltage of diode is calculated as in (4).

$$
V_{D(\max )}=-\frac{V_{I N}}{n}+V_{O}
$$

When the switch is turned off, the polarity of the secondary winding is reversed and diode turns on. Stored energy in the magnetizing inductor supplies to the resistive load and current of secondary winding increases linearly. The initial value of the secondary current is determined by the multiplication of peak current of primary winding and the turns ratio of the transformer $\left(\mathrm{N}_{\mathrm{P}} / \mathrm{N}_{\mathrm{S}}\right)$. Current of the secondary winding is calculated as in (5).

$$
I_{S E C}=\frac{I_{\text {peak }} N_{P}}{N_{S}}-\frac{\left(V_{O}+V_{D}\right) t_{O F F} N_{P}}{N_{S} L_{M}}
$$

In (5), $I_{\text {peak }}$ is the peak current of primary winding, $N_{P}$ and $\mathrm{N}_{S}$ are the number of turns of primary and secondary windings, $\mathrm{V}_{\mathrm{O}}$ is the output voltage of flyback converter, $\mathrm{V}_{\mathrm{D}}$ is the voltage of drop of the diode, $t_{\mathrm{OFF}}$ is the conduction time of the diode. When the switch is turned off, voltage stress on the switch is the sum of the input voltage and reverse voltage due to the current of secondary side. Therefore, the switch has more voltage stress in the flyback compared with the non- isolated buck-boost converter. The voltage across the switch is calculated as in (6).

$$
V_{D S(\max )}=V_{I N}+n V_{O}+V_{\text {leak }}
$$

In (6), $\mathrm{V}_{\text {leak }}$ is the leakage voltage which is the result of parasitic inductance of primary and secondary windings. In order to select proper switch, leakage inductance, windings ratio are taken into account. The output of the flyback converter consists of a capacitor and load. This capacitor is generally is specified by the root mean square current and the permissible voltage ripple. The minimum value of this capacitor is calculated as in (7).

$$
C_{\min }=\frac{D_{\max } V_{O}}{f_{P} R_{L \min } \Delta V_{O}}
$$

In (7), $\mathrm{C}_{\min }$ is the minimum value of the output capacitor, $D_{\max }$ is the maximum value of duty ratio, $R_{L m i n}$ is the minimum value of the load resistance, $f_{p}$ is the switching frequency and $\Delta \mathrm{V}_{\mathrm{O}}$ is the voltage ripple of the capacitor. On the other hand, the relationship between input and output voltage, which is named as DC transfer function, is important for an MPPT application. So, the output voltage of flyback can be formulated by input voltage, duty ratio and windings ratio as in (8).

$$
V_{O}=V_{I N} \frac{D}{1-D} \frac{N_{S}}{N_{P}}
$$

It is clear in Fig. 2 that, the windings of the flyback transformer do not carry current between $t=o f f$ and $i t=T_{P}$ in DCM operation. On the other hand, in BCM operation, primary and secondary windings carry current in different time period by triangular waveform. When the switch is turned on current of primary winding increases and energy is stored in the transformer. Between $\mathrm{t}=0$ and $\mathrm{t}=\mathrm{t}_{\mathrm{ON}}$, diode is reverse biased due to the polarity of secondary winding. When the switch is turned off, all energy stored in the transformer supplies the output capacitor and the load on the secondary side between $\mathrm{t}=\mathrm{t}_{\mathrm{ON}}$ and $\mathrm{t}=\mathrm{t}_{\mathrm{P}}$. In CCM operation, the windings of the transformers carry current in trapezoid form and there is no current shortage in a switching period as presented in Fig. 2. Some of the energy stored in the transformer is not transferred to the secondary side of the flyback.

\section{Flyback MPPT Converter}

Voltage of PV module changes in a big interval under PSCs. That is, input voltage of a converter changes in a large range. Therefore, buck-boost converters are the best choices for MPPT applications since they have the ability to increase and decrease the voltage. In addition, the flyback converter performs efficiently below one hundred watts and this power level is proper for SML MPPT. A typical block diagram of flyback MPPT is presented in Fig. 3. 


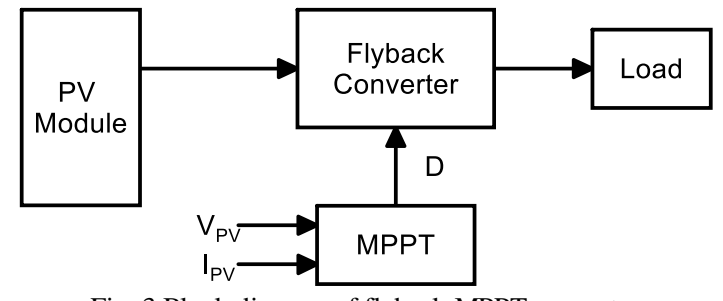

Fig. 3 Block diagram of flyback MPPT converter

In order to realize MPPT in flyback converter, transfer function between PV module and resistive load is obtained. First, power of PV module is given in (9).

$$
P_{P V}=V_{P V} I_{P V}=I_{P V} R_{P V}
$$

In (9), $V_{P V}$ and $I_{P V}$ are the voltage and current of $P V$ module, respectively. The $\mathrm{R}_{\mathrm{PV}}$ is the equivalent resistance of $\mathrm{PV}$ module. The voltage of a PV module is equal to;

$$
V_{P V}=I_{P V} R_{P V}
$$

For output of flyback converter, output power and output voltage are given by (11) and (12), respectively.

$$
\begin{gathered}
P_{O}=V_{O} I_{O}=I_{O}^{2} R_{L} \\
V_{O}=I_{O} R_{L}
\end{gathered}
$$

In (11) and (12), $V_{O}$ and $I_{O}$ are the output voltage and output current, respectively. Assuming the converter loss is zero, power, balance can be easily written as follows.

$$
P_{I N}=P_{O}=V_{P V} I_{P V}=V_{O} I_{O}
$$

By using (9) - (13), the equivalent resistance of PV module can be formulated as in (14), which is the core of the MPPT operation for flyback converters.

$$
R_{P V}=R_{L} \frac{(1-D)^{2}}{D^{2}}\left(\frac{N_{P}}{N_{S}}\right)^{2}
$$

\section{SimUlation Results}

In order to validate the benefits of the SML MPPT with respect to the module level MPPT, some simulation studies have been performed in MATLAB Simulink software. SML MPPT owning three flyback converters has been modelled. A SML MPPT model is presented in Fig. 4. In this model, PV module has three bypass diodes. Each submodule is connected to its own flyback converter. MPPT is realized individually by P\&O. On the other hand, module level MPPT model is presented in Fig. 5. The main parameters of the PV module and flyback converter used in simulation studies are listed in Table I and Table II, respectively.

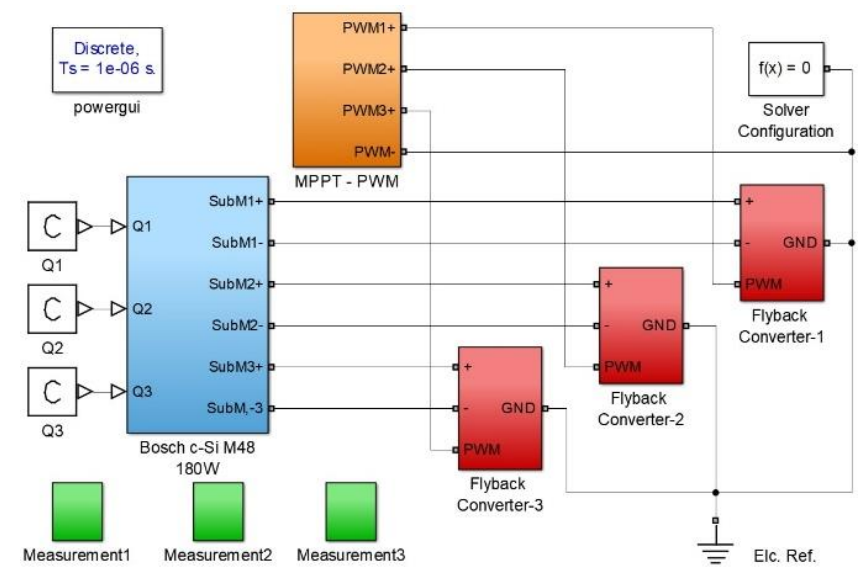

Fig. 4 Simulink model of the flyback converter based SML MPPT

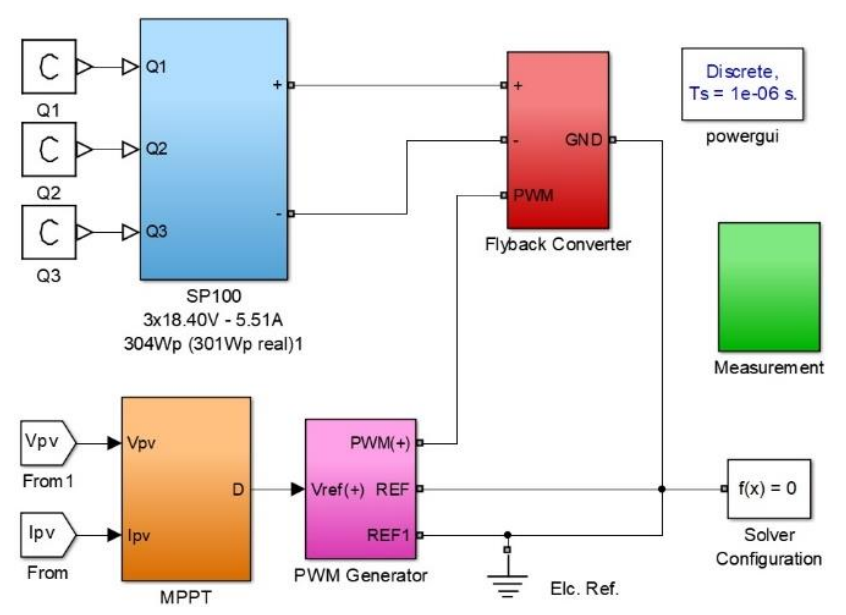

Fig. 5 Simulink model of the module level MPPT

TABLE I

SPECIFICATIONS OF THE PV MODULE

\begin{tabular}{|l|c|}
\hline Bosch PV Module c-Si M 48 & Value \\
\hline Short circuit current & $8.5 \mathrm{~A}$ \\
\hline Open circuit voltage & $28.9 \mathrm{~V}$ \\
\hline Maximum power voltage & $23.4 \mathrm{~V}$ \\
\hline Maximum power current & $7.9 \mathrm{~A}$ \\
\hline Maximum power & $180 \mathrm{~W}$ \\
\hline Bypass diodes & 3 \\
\hline
\end{tabular}

TABLE II

SPECIFICATIONS OF THE FLYBACK CONVERTERS IN SML MPPT

\begin{tabular}{|l|c|}
\hline Features & Value \\
\hline Input / output capacitor & $1000 \mu \mathrm{F} / 100 \mu \mathrm{F}$ \\
\hline Magnetizing inductance & $40 \mathrm{mH}$ \\
\hline Windings turns ratio & 0.5 \\
\hline Switching frequency & $20 \mathrm{kHz}$ \\
\hline Duty Step / Sample time & $0.1 \% / 1 \mathrm{~ms}$ \\
\hline
\end{tabular}

Two shading scenarios are created to verify the superior performance of the SML MPPT. First, submodules of the PV module receive $400 \mathrm{~W} / \mathrm{m}^{2}, \quad 700 \mathrm{~W} / \mathrm{m}^{2}$ and $800 \mathrm{~W} / \mathrm{m}^{2}$, respectively. The initial value of duty ratio and the step size is set to $50 \%$ and $0.1 \%$, respectively. In the first simulation 
result, all submodules perform their own MPPT by $\mathrm{P} \& \mathrm{O}$ algorithm. A resistor valued by $10 \Omega$ is connected to the output of the each flyback converter. The P-V curve of the first P-V characteristic is presented in Fig. 6. The results of the first irradiance profile are presented in Fig. 7. It is clear in Fig. 7.a that all submodules generated different power and reaches their own MPPT with different tracking speed since they receive different irradiance. While the sub-module-1 receiving $400 \mathrm{~W} / \mathrm{m}^{2}$ tracks the MPP in 18 milliseconds (ms), submodule- 2 receiving $500 \mathrm{~W} / \mathrm{m}^{2}$ tracks its own MPP in $100 \mathrm{~ms}$. These times may change and/or can be optimized by the proper selection, initial value of duty ratio and using adaptive step size. In the first case, total tracking efficiency is calculated as $92.6 \%$ in $250 \mathrm{~ms}$.

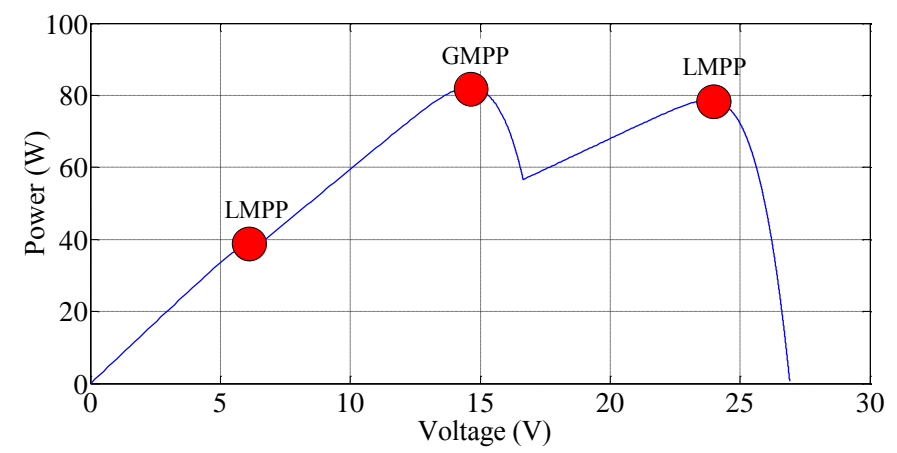

Fig. 6. P-V curve of $400 \mathrm{~W} / \mathrm{m}^{2}-500 \mathrm{~W} / \mathrm{m}^{2}-800 \mathrm{~W} / \mathrm{m}^{2}$

In the second irradiance profile, values of irradiances are $300 \mathrm{~W} / \mathrm{m}^{2}, 600 \mathrm{~W} / \mathrm{m}^{2}$ and $1000 \mathrm{~W} / \mathrm{m}^{2}$. Voltage, current, power variations of the submodules and duty ratio variations of each flyback converters are given in Fig. 8. a-d. Each submodule performs its own MPPT by $\mathrm{P} \& \mathrm{O}$ algorithm. Performing independent MPPT provides $100 \%$ tracking efficiency at
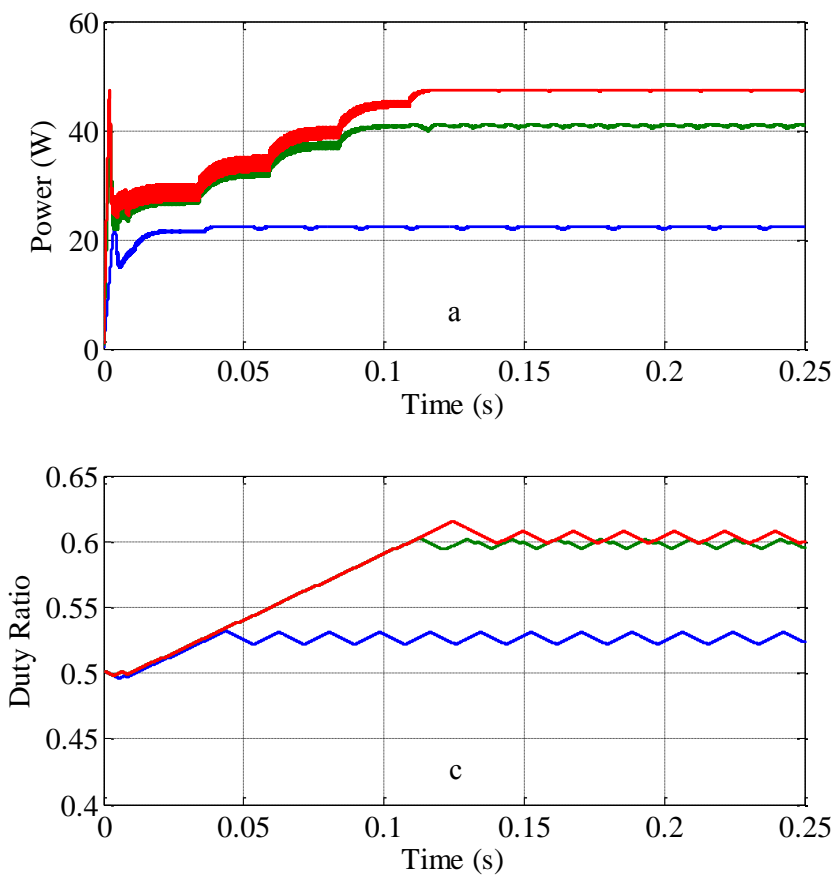

Fig. 7. Simulation results of irradiance profile-1 for SML MPPT a) Power b) Voltage c) Duty ratio d) Current steady state condition. Tracking efficiencies in $250 \mathrm{~ms}$ are $97.91 \%, 93.28 \%$ and $84.16 \%$ for submodule-1, submodule-2 and submodule-3, respectively. Total tracking efficiency is $91.81 \%$. For SML MPPT, tracking efficiency is very big since global MPPT is realized regardless of the irradiance values.

In module level MPPT approach, multiple peak points occur on the P-V curve under PSCs due to the presence of bypass diodes included in a module. In addition, the available power of PV module decreases in a PSC. The P-V curve of the second irradiance profile is presented in Fig. 9. In the first case, three peak points occur on the P-V curve due to three different irradiance. It is clear in Fig. 8 that there are three peak points. Two of them are local MPP and another peak point is global MPP. Middle of the peak point corresponds to the global peak point. Power at global MPP is $82.22 \mathrm{~W}$. But, MPPT fails at the first local MPP and power at steady state is about $78 \mathrm{~W}$. In this case, tracking efficiency is calculated as $69.82 \%$. However, for the same irradiance profile, SML MPPT extracts $110.92 \mathrm{~W}$ from the PV module. That is, SML MPPT strategy generates more power by $34.9 \%$. The results of the module level MPPT are presented in Fig. 10.

In the second shading scenario, GMPP is located in the middle MPP region as shown in Fig. 9. Power at global MPP is 73.51W. P\&O algorithm fails at the first local MPP (LMPP) and PV module generated about $60 \mathrm{~W}$ at this point. PV module generates less power by $18.37 \%$ compared with the global maximum power point (GMPP) seen in the Fig. 9. Tracking efficiency is calculated as $65.37 \%$ in $250 \mathrm{~ms}$. On the other hand, for the same shading scenario, SML MPPT approach obtains more power by $85.9 \%$ with respect to the module level MPPT.
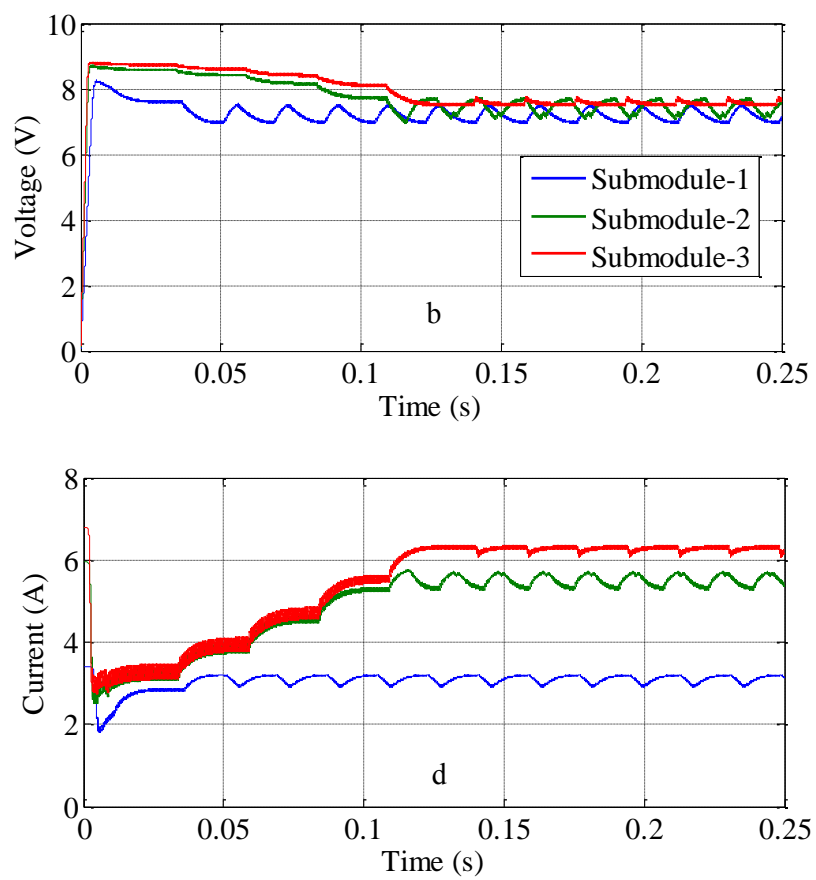

a) Power b) Voltage c) Duty ratio d) Current 

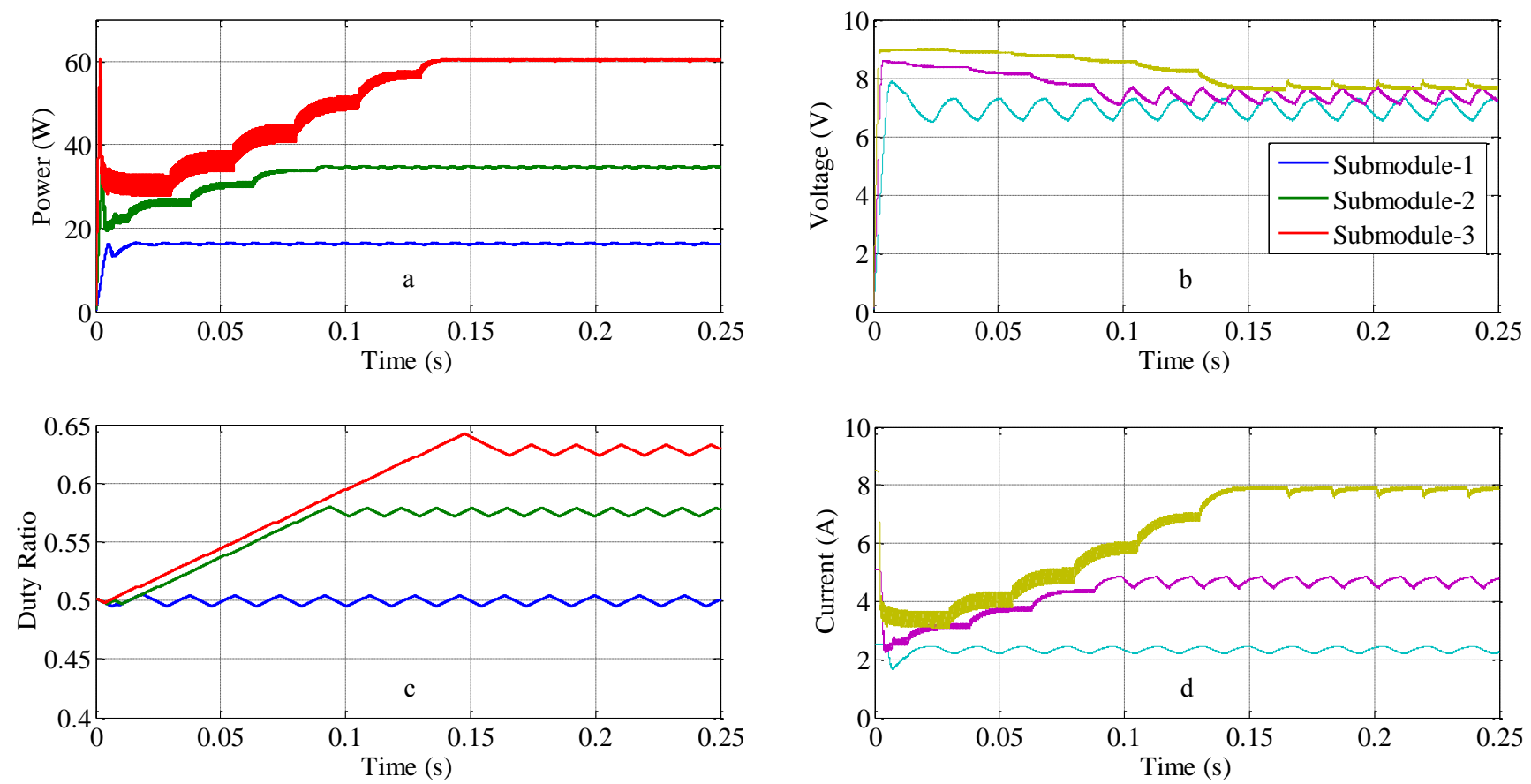

Fig. 8. Simulation results of irradiance profile-2 for SML MPPT a) Power b) Voltage c) Duty ratio d) Current

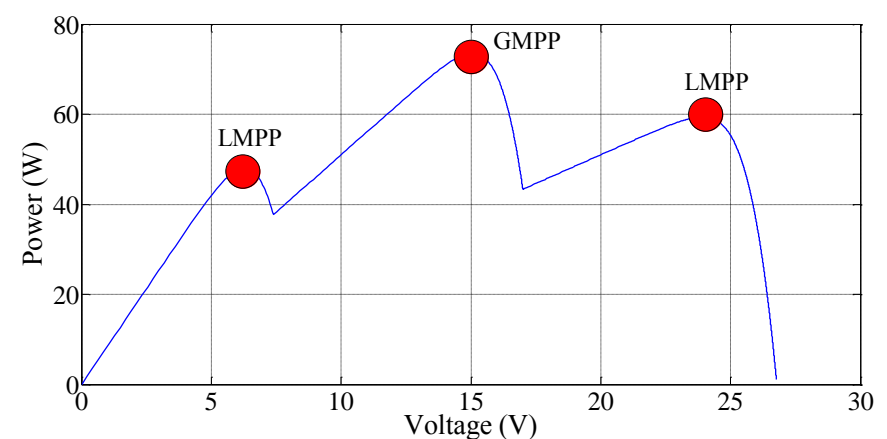

Fig. 9. P-V curve of $400 \mathrm{~W} / \mathrm{m}^{2}-500 \mathrm{~W} / \mathrm{m}^{2}-800 \mathrm{~W} / \mathrm{m}^{2}$

\section{DISCUSSION}

Simulation results show that the module level MPPT strategy has superior performance than module level MPPT. The numerical results of the simulation studies performed are listed in Table III. It is clear that submodule level performs high quality MPPT with P\&O algorithm. All submodules achieved satisfactory efficiencies in $250 \mathrm{~ms}$. It is obvious that tracking efficiencies increase if simulation time is selected bigger. The differences between the efficiency values depend on the irradiance value and the initial value of the duty ratio. On the other hand, module level MPPT fails at the first peak point since $\mathrm{P} \& \mathrm{O}$ is one of the hill climbing based technique. Tracking efficiency is very small in module level MPPT. Global MPP may not be tracked.

\section{CONCLUSIONS AND FUTURE WORK}

PV energy systems have small capacity factor since they have small power conversion efficiency and low full time operation capacity. Therefore, it is obliged that these systems should be operated with maximum available efficiency. Thus,
TABLE III NUMERICAL RESULTS OF SIMULATION STUDIES

\begin{tabular}{|l|c|c|c|}
\hline \multirow{2}{*}{ Irradiance Profile } & \multicolumn{3}{|c|}{ Submodule Level MPPT } \\
\hline \multirow{2}{*}{$400-700-800 \mathrm{~W} / \mathrm{m}^{2}$} & $97.67 \%$ & $91.35 \%$ & $88.8 \%$ \\
\cline { 2 - 4 } & \multicolumn{3}{|c|}{ Average: $92.6 \%$} \\
\hline \multirow{2}{*}{$300-600-1000 \mathrm{~W} / \mathrm{m}^{2}$} & $97.91 \%$ & $93.38 \%$ & $84.16 \%$ \\
\cline { 2 - 3 } & \multicolumn{3}{|c|}{ Average: $91.81 \%$} \\
\hline Irradiance Profile & \multicolumn{3}{|c|}{ Module Level MPPT } \\
\hline $400-700-800 \mathrm{~W} / \mathrm{m}^{2}$ & \multicolumn{3}{|c|}{$69.82 \%$} \\
\hline $300-600-1000 \mathrm{~W} / \mathrm{m}^{2}$ & \multicolumn{3}{|c|}{$65.37 \%$} \\
\hline
\end{tabular}

MPPT is an important process for these systems. In PSCs, the available power of the PV system decreases harshly and module level MPPT do not often provide available power. In this study, flyback converter based SML MPPT approach has been presented which is the improved strategy in MPPT applications. Design steps of CCM operated flyback converter are explained and theory of flyback MPPT is studied briefly. Advantages of the SML MPPT with respect to the module level MPPT are validated for two shading scenarios. As expected, module level MPPT fails at local MPP and provides low tracking efficiency with $\mathrm{P} \& \mathrm{O}$ algorithm. Simulation results show that SML MPPT performs superior than module level MPPT in PSCs. While total tracking efficiency is about 92.2\% on average for SML MPPT, module level MPPT concept reaches to $67.59 \%$ efficiency. On the other hand, available power to be obtained is always bigger in SML MPPT than module level MPPT. In future studies, advantages of the SML MPPT approach will be validated by experimental studies. 

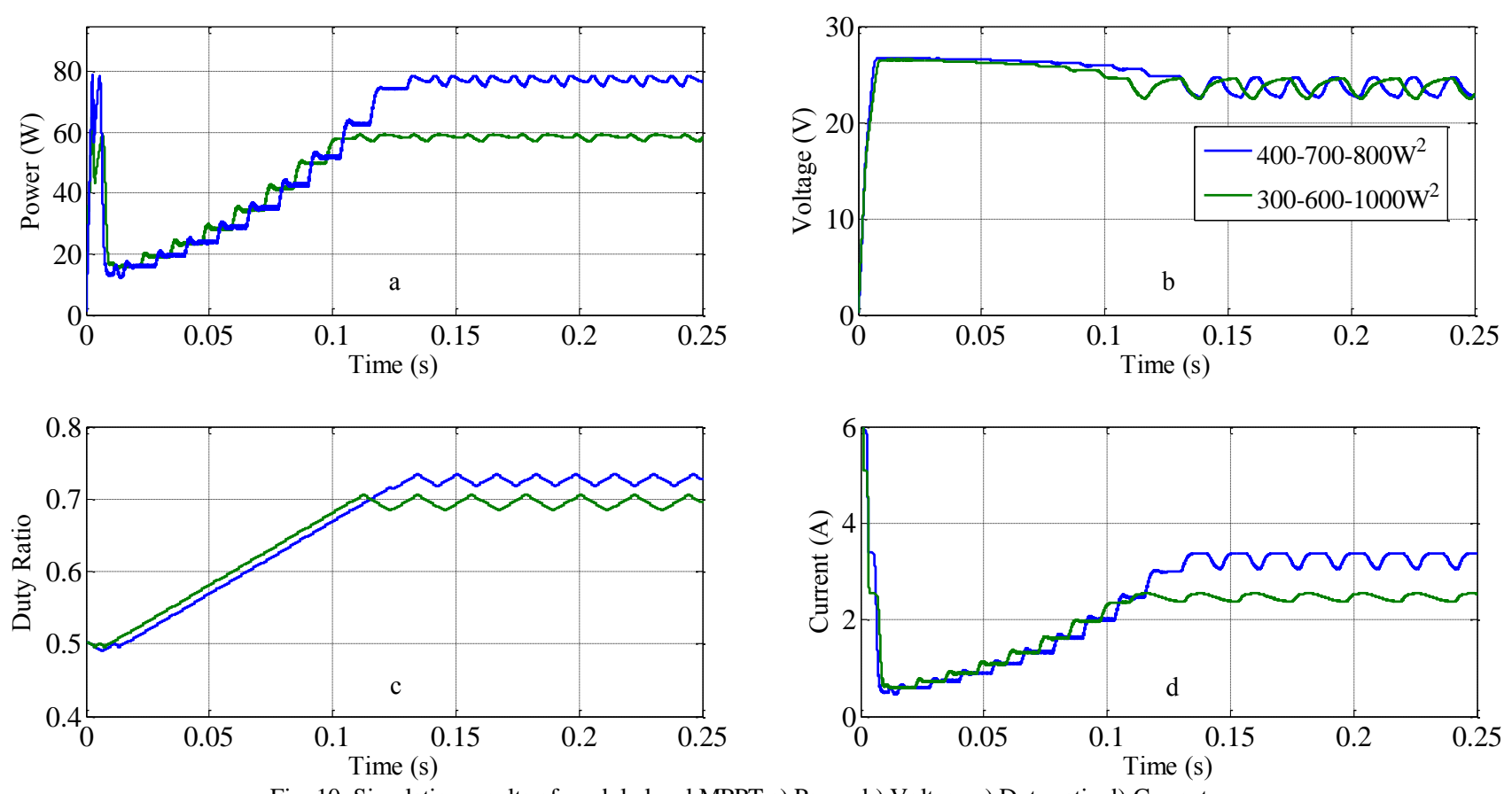

Fig. 10. Simulation results of module level MPPT a) Power b) Voltage c) Duty ratio d) Current

\section{REFERENCES}

[1] Başoğlu M.E., Çakır B., An improved incremental conductance based MPPT approach for PV modules, Turkish Journal of Electrical Engineering \& Computer Sciences, vol. 23, no. 6, pp. 1687-1697, 2015.

[2] Başoğlu M.E., Çakır B., Comparisons of MPPT performances of isolated and non-isolated DC-DC converters by using a new approach, Renewable \& Sustainable Energy Reviews, vol. 60, pp. 1100-1113, 2016.

[3] Başoğlu M.E., Çakır B., A novel voltage-current characteristic based global maximum power point tracking algorithm in photovoltaic systems, Energy, vol. 112, pp. 153-163, 2016.

[4] Kasa N., Iida T., Chen L., Flyback inverter controlled by sensorless current MPPT for photovoltaic power system, IEEE Transactions on Industrial Electronics, vol. 52, no. 4, pp. 1145-1152, 2005.

[5] Mazumdar P, Enjeti P.N., Balog R.S., Analysis and design of smart PV modules, IEEE Journal of Emerging and Selected Topics in Power Electronics, vol. 2, no. 3, pp. 451-459, 2014.

[6] Pragallapati N., Agarwal V., Flyback configuration based micro-inverter with distributed MPPT of partially shaded PV module and energy recovery scheme, IEEE 39th Photovoltaic Specialists Conference, Tampa, USA, pp. 2927-2931, 2013.

[7] Lee J., Lee J. S., Lee K., Current sensorless MPPT method for a PV flyback microinverters using a dual-mode, International Power Electronics Conference, Hiroshima, pp. 532-537, 2014.

[8] Kim Y., Kim J., Ji Y., Won C. Lee T., Flyback inverter using voltage sensorless MPPT for AC module systems, International Power Electronics Conference, Sapporo, pp. 948-953, 2010.

[9] Zhang W.P., Li J., Mao P., A novel isolated-port voltage equalizer for photovoltaic systems under mismatch conditions, $43^{\text {rd }}$ Annual Conference of the IEEE Industrial Electronics Society, Beijing, pp. 639644, 2017.

[10] Sher H.A., Rizvi A.A., Addoweesh K.E., Al-Haddad K., A., Single-stage stand-alone photovoltaic energy system with high tracking efficiency, IEEE Transactions on Sustainable Energy, vol. 8, no. 2, pp. 755-782, 2017.

[11] Pilawa-Podgurski R.C.N., Perreault D.J., Submodule integrated distributed maximum power point tracking for solar photovoltaic applications, IEEE Transactions on Power Electronics, vol. 28, no. 6, pp. 2957-2967, 2013.

[12] Grasso A.D., Pennisi S., Ragusa M., Tina G.M., Ventura C., Performance evaluation of a multistring photovoltaic module with distributed DC-DC converters, IET Renewable Power Generation, vol. 9, no. 8, pp. 935-942, 2015.
[13] Qin S., Barth C.B., Pilawa-Podgurski R.C.N., Enhancing microinverter energy capture with submodule differential power processing, IEEE Transactions on Power Electronics, vol. 31, no. 5, pp. 3575-3585, 2016.

[14] Wang F., Zhu T., Zhuo F., Yang Y., Analysis and comparison of FPP and DPP structure based DMPPT PV system, $8^{\text {th }}$ International Power Electronics and Motion Control Conference, Hefei, pp. 1-5, 2016.

[15] Pragallapati N., Agarwal V., Distributed PV power extraction based on a modified interleaved SEPIC for nonuniform irradiation conditions, IEEE Journal of Photovoltaics, vol. 5, no. 5, pp. 1442-1453, 2015.

[16] Bose S.M., Badawy O., Sozer Y., A novel differential power processing architecture for a partially shaded PV string using distributed control, IEEE Energy Conversion Congress and Exposition, Portland, pp. 62206227, 2018.

[17] TopSwitch Flyback Design Methodology, Application Note AN-16, https://ac-dc.power.com/system/files_force/product-docs/an16.pdf, (accessed: 20.01.2019).

[18] Kazmierczuk, M.K., 2008, Pulse-width modulated DC-DC power converters, John Wiley \& Sons, Ltd. United Kingdom, pp. 191-195.

\section{BIOGRAPHY}

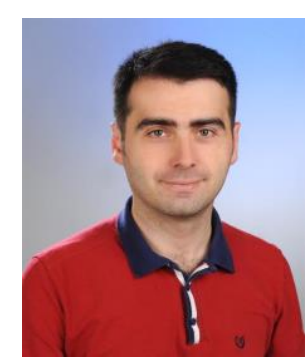

MUSTAFA ENGİN BAŞOĞLU was born in 1988. He received the M.Sc. degree of Electrical Engineering at Kocaeli University, Turkey in 2013. He receives $\mathrm{Ph}$.D. in 2017 with thesis "Development and implementation of a new maximum power point tracking method for photovoltaic systems". From 2012, he is research assistant in the department of Electrical Engineering in University Kocaeli. From 2018, he is assistant professor in Electrical and Electronics Department of Gümüşhane University. His research interests include: photovoltaic systems, renewable energy, maximum power point tracking algorithms, power electronics, switch mode power supplies and control of electrical machines. 